\title{
Effects of mangrove apple (Sonneratia caseolaris) fruit extract on oxidative stability of palm olein under accelerated storage
}

\author{
${ }^{1}$ Yoong, M.H. and ${ }^{1,2, *}$ Tengku Rozaina, T.M. \\ ${ }^{1}$ Faculty of Fisheries and Food Science, Universiti Malaysia Terengganu, 21030 Kuala Nerus, Terengganu, \\ Malaysia \\ ${ }^{2}$ Institute of Tropical Biodiversity and Sustainable Development, Universiti Malaysia Terengganu, 21030, \\ Kuala Nerus, Terengganu, Malaysia
}

\author{
Article history: \\ Received: 19 August 2020 \\ Received in revised form: 26 \\ September 2020 \\ Accepted: 17 November 2020 \\ Available Online: 13 \\ February 2021
}

\section{Keywords:}

Mangrove apple fruit extract, Palm olein,

Antioxidant properties,

Oxidative stability,

Accelerated storage

DOI:

https://doi.org/10.26656/fr.2017.5(1).445

\begin{abstract}
Palm olein is commonly used in cooking and food processing, however, it is susceptible to oxidation due to its high unsaturated fatty acids content. An antioxidant is added to the oil by oil manufacturer to inhibit lipid oxidation and increase the shelf life of the oil. However, most of the antioxidants are synthetic antioxidants that may not be safe for consumption and decomposed at high temperature during frying or processing. In this study, the antioxidant properties of mangrove apple fruit extract (MAFE), as well as the oxidative stability of palm olein with and without MAFE, were investigated. Palm olein added with MAFE (100 and $200 \mathrm{ppm}$ ) and without MAFE were kept at $65^{\circ} \mathrm{C}$ in an oven for 24 days under accelerated storage. The results showed that MAFE contained high total flavonoid compound $(26.06 \pm 0.30 \mathrm{mg}$ QCE/g extract) and total phenolic compound $\left(12.21 \pm 1.31 \mathrm{mg}\right.$ GAE$/ \mathrm{g}$ extract). The $\mathrm{IC}_{50}$ values of antioxidant activities of MAFE calculated by DPPH and ABTS $^{*+}$ were $31.16 \pm 0.76 \mu \mathrm{g} / \mathrm{mL}$ and $97.32 \pm 3.27 \mu \mathrm{g} / \mathrm{mL}$, respectively. The palm olein samples added with MAFE showed significantly lower peroxide value, $p$-anisidine value, TOTOX value, conjugated dienes and conjugated trienes after 24 days of storage compared to the palm olein without MAFE (control sample). The oxidative stability of palm olein added with $200 \mathrm{ppm}$ MAFE was higher compared to the palm olein added with $100 \mathrm{ppm}$ MAFE and control sample. Therefore, MAFE has the potential to be used as a source of natural antioxidant to reduce the lipid oxidation and prolong the shelf life of food products.
\end{abstract}

\section{Introduction}

Palm olein is a common commercial vegetable oil in Malaysia. It is the liquid fraction obtained by fractionation of palm oil after crystallisation at a controlled temperature, while the solid fraction is called palm stearin (Soares et al., 2009). The palm olein has low oxidative stability due to it is high in unsaturated fatty acid content (55\%), mainly oleic acid (C18:1n9) and linoleic acid (C18:2n6) (Che Man and Tan, 1999; Gan et al., 2005; Soares et al., 2009). Furthermore, the free fatty acids (FFA), moisture, trace metals and other impurities in the palm olein have limited the shelf life of palm olein and cause off-odour and off-flavour after oxidised (Damanik and Murkovic, 2018).

The acceptability and market value of vegetable oils are mainly affected by the quality and stability of the oil. Hence, it is crucial to maintain the quality of oil in the oil manufacturing industry. One of the most significant indicators for maintaining the quality of edible oils is oxidative stability (Tan et al., 2002). According to Gan et al. (2005), oxidation deteriorates oil or fat. It produced a pungent and offensive off-flavour, discolouration, polymerisation and destruction of vitamins (A, D, E, K and C), essential fatty acids, other nutrients, or enzymes by the production of the toxic or physiologically active compounds. Moreover, oxidation will also cause the degradation of physiological properties of food, such as flavour, colour and texture. Formation of numerous volatile and non-volatile compounds will be occurred due to the chemical reactions by oxidation, which included FFA, aldehydes, di- and mono-glycerides and polymeric triglycerides (Maskan and Horuz, 2017).

Various accelerated stability tests are carried out to evaluate the stability of oils and fats rapidly. The working principle of most of the accelerated tests is 
exposing oil samples to elevated temperatures in the presence of excess amounts of air or oxygen to speed up the oxidation process. The accelerated stability or oxidation tests most widely used are the Schaal oven test and the active oxygen method (AOM) (Tan et al., 2002). The Schaal oven test was used in previous studies to measure the oxidative stability of oils. For example, dark brown bottles were used to store sunflower oil in an oven at $65^{\circ} \mathrm{C}$ for 24 days (Yim et al., 2013; Chong et al., 2015; Wang et al., 2018) and palm olein in an electric hot air oven at $70^{\circ} \mathrm{C}$ for 30 days with 8 hours heating cycle for each day (Womeni et al., 2016).

Previously, the synthetic antioxidants were added to the oil by oil manufacturers to minimise the oxidative deterioration of the oil. Synthetic antioxidants such as butylated hydroxyanisole (BHA), butylated hydroxytoluene (BHT), propyl gallate (PG) and tertiary butyl hydroquinone (TBHQ), are cheaper than natural antioxidants (Maskan and Horuz, 2017). However, the commercial use of synthetic antioxidants is restricted in several countries (Womeni et al., 2016) and also an increasing consumer awareness of food additives due to potential toxicity present as the use of synthetic antioxidants can cause many health risks, including cancer, cardiovascular diseases and carcinogenesis (Hou, 2003). For example, the maximum usage of TBHQ in European Union, China, United States of America, Australia, Brazil, New Zealand, and the Philippines is $200 \mathrm{mg} / \mathrm{kg}$ (Makahleh et al., 2015). Furthermore, the synthetic antioxidants are unstable at high temperature during frying or processing because they can easily evaporate and decomposed, which related to their chemical structure (Guo et al., 2016). Therefore, there is increasing usage of natural antioxidants as alternatives to synthetic compounds due to the issue of safety. Natural antioxidants can be extracted from many plants, including herbs and spices that have been reported to have varying degrees of antioxidant activities in fats and oils (Che Man and Tan, 1999). Many previous studies used extracts from plants or spices to replace the synthetic antioxidants, such as rosemary (Guo et al., 2016), rosemary and sage (Che Man and Jaswir, 2000), soursop flowers (Womeni et al., 2016), turmeric leaf (Fatihanim et al., 2009) and mangosteen peel (Wang et al., 2018).

Sonneratia caseolaris (L.) Engl. in the family of Sonneratiaceae, also known as mangrove apple, is a small to medium-sized tree, which can grow up to $15 \mathrm{~m}$ to $20 \mathrm{~m}$ tall, with oblong or obovate-elliptic coriaceous leaves and groups of 1 to 3 large red flowers together (Sadhu et al., 2006; Dam Roy et al., 2009). The mangrove apple fruit contained dietary fibre, vitamins and flavonoids, including luteolin and luteolin 7-O- $\beta$ glucoside (Sadhu et al., 2006), phenolic compounds (Minh, 2019), antioxidative, antimicrobial, anticholesterol and anti-diabetic properties (Jariyah et al., 2014; Simlai et al., 2014; Thuoc et al., 2018). Therefore, the ripe mangrove apple is a potential source of natural antioxidants owing to its significant antioxidant activities. The objectives of this study are to determine the antioxidants properties of mangrove apple fruit extract (MAFE) as well as the oxidative stability of palm olein with and without MAFE during accelerated storage.

\section{Materials and methods}

\subsection{Materials}

Refined palm olein (Bagus; Sime Darby, Malaysia) was purchased in the local market in Kuala Nerus, Terengganu. The mangrove apple (Sonneratia caseolaris) fruits were picked from the mangrove apple trees in the mangrove swamp area in Pulau Duyung, Kuala Terengganu, Terengganu, Malaysia. The fruits were flattened-round, hard and green fleshy fruit in a flattened calyx tube. The mangrove apple fruits were stored at $4^{\circ} \mathrm{C}$ before extraction.

\subsection{Extraction of mangrove apple fruits}

The whole mangrove apple fruits without calyx tube were cleaned, dried and grounded together with the seeds by MX-AC400 mixer grinder (Panasonic, Malaysia) into powder form before extraction. Extraction of mangrove apple fruits was carried out according to $\mathrm{Wu}$ et al. (2009). The pericarp with seeds of mangrove fruits was soaked in $95 \%$ ethanol (HmbG Chemicals, Malaysia) in a beaker at room temperature $\left(28^{\circ} \mathrm{C}\right)$ with a ratio of $1: 2$ (270 g fruit: $540 \mathrm{~mL}$ ethanol). The beaker was then covered with aluminium foil and placed on an orbital shaker (KS-501 digital, IKA, Germany) at $150 \mathrm{rpm}$ for $60 \mathrm{~min}$ at room temperature for the first extraction. The mixture was centrifuged by refrigerated centrifuge (1590R, Gyrozen Limited Company, Korea) for 10 mins at $4000 \mathrm{rpm}$ and the supernatant was filtered using Whatman No. 1 filter paper. The residue was re-extracted twice for the second and third time. After that, the three extracts were combined and concentrated using a rotary evaporator (Buchi, Switzerland) at $45^{\circ} \mathrm{C}$.

\subsection{Analysis of total flavonoid content}

Analysis of total flavonoid content (TFC) was conducted according to the aluminium chloride $\left(\mathrm{AlCl}_{3}\right)$ colourimetry method by Anokwuru et al. (2011) with slight modification. The mangrove apple fruit extract (MAFE) was diluted with distilled water until it becomes 
$100 \mu \mathrm{g} / \mathrm{mL}$. The standard curve was prepared by diluting quercetin in distilled water $(0,25,50$ and $100 \mu \mathrm{g} / \mathrm{mL})$. Distilled water $(4 \mathrm{~mL})$ was added to $1 \mathrm{~mL}$ of the diluted MAFE or quercetin (standard) in a respective test tube. After that, $0.3 \mathrm{~mL}$ of $5 \%$ sodium nitrite $\left(\mathrm{NaNO}_{2}\right)(\mathrm{R} \& \mathrm{M}$ Chemicals, United Kingdom) solution was added into the test tube. At $5 \mathrm{mins}, 0.3 \mathrm{~mL}$ of $10 \% \mathrm{AlCl}_{3}$ (R\&M Chemicals, United Kingdom) was added, followed by 2 $\mathrm{mL}$ of $1 \quad \mathrm{M}$ sodium hydroxide $(\mathrm{NaOH}) \quad(\mathrm{R} \& \mathrm{M}$ Chemicals, United Kingdom) at 6 min. Distilled water $(2.4 \mathrm{~mL})$ was then added to the test tube and mixed well. The absorbance of the reaction mixture was read at 510 $\mathrm{nm}$ using UV-VIS spectrophotometer (Spectroquant Pharo 300, Merck KGaA, Germany). Total flavonoid content was determined as quercetin equivalents (mg QCE/g of extract).

\subsection{Analysis of total phenolic content}

The total concentration of phenolic content (TPC) in the extract was carried out according to a Folin-Ciocalteu method by Hossain et al. (2013) with slight modification. Gallic acid (GA) was used as the standard $(0,25,50,75$ and $100 \mu \mathrm{g} / \mathrm{mL}$ ) and expressed as gallic acid equivalents (mg GAE/g extract). The sample extract was diluted with distilled water to a concentration of $100 \mu \mathrm{g} / \mathrm{mL}$. Then, $1.0 \mathrm{~mL}$ of diluted extract or gallic acid (Merck KGaA, China) was mixed with $1.0 \mathrm{~mL}$ of Folin-Ciocalteu's reagent (R\&M Chemicals, United Kingdom) and vortexed for 5 seconds. After that, $1.0 \mathrm{~mL}$ of a $10 \%(\mathrm{w} /$ v) sodium carbonate (HmbG Chemicals, Germany) aqueous solution was added to the mixture. The mixture was incubated at room temperature for $1 \mathrm{hr}$. The absorbance of the mixture was measured at $700 \mathrm{~nm}$ by spectrophotometer (Spectroquant Pharo 300, Merck KGaA, Germany).

\subsection{DPPH radical scavenging assay}

2,2-diphenyl-1-picrylhydrazyl (DPPH) radical scavenging assay of the mangrove apple extract was carried out according to a modified Thuoc et al. (2018) method. The DPPH solution $(0.2 \mathrm{mM})$ was prepared by dissolving $7.9 \mathrm{mg}$ of DPPH (Sigma-Aldrich, USA) in $100 \mathrm{~mL}$ of $95 \%$ ethanol. The sample extract and ascorbic acid (HmbG Chemicals, Germany) were diluted to a concentration of $10,50,90,130$ and $170 \mu \mathrm{g} / \mathrm{mL}$. Then, $900 \mu \mathrm{L}$ of ethanolic DPPH solution was added to $100 \mu \mathrm{L}$ of sample extract or ascorbic acid for each concentration. The mixture was shaken vigorously for $1 \mathrm{~min}$ and allowed to react at room temperature $\left(28^{\circ} \mathrm{C}\right)$ in dark condition for 30 mins. The absorbance of resulting mixture was measured at $517 \mathrm{~nm}$ by spectrophotometer (Spectroquant Pharo 300, Merck KGaA, Germany) and converted to percentage inhibition (\% inhibition), using the following equation:
$\%$ DPPH Inhibition $=\frac{A_{\text {blank }}-A_{\text {sample }}}{A_{\text {blank }}} \times 100$

Where $A_{\text {blank }}=$ Absorbance of the blank sample and $A_{\text {sample }}=$ absorbance of the sample.

Ascorbic acid (Vitamin C) solution was used as a positive control. The half-maximal inhibitory concentration $\left(\mathrm{IC}_{50}\right)$ was reported as the amount of antioxidant required to decrease the initial DPPH concentration by $50 \%$.

\subsection{ABTS $^{+}$radical scavenging assay}

Analysis of 2.2,-azino-bis-(3-ethyl benzothiazoline-6 -sulfonic acid) radical cation (ABTS ${ }^{\circ+}$ ) scavenging assay was determined according to AlShaal et al. (2019). The $\mathrm{ABTS}^{\circ+}$ solution was prepared by reacting equal quantities of $7 \mathrm{mM}$ of ABTS (Sigma-Aldrich, USA) and $2.45 \mathrm{mM}$ of sodium persulphate $\left(\mathrm{Na}_{2} \mathrm{~S}_{2} \mathrm{O}_{8}\right)$ (R\&M Chemicals, United Kingdom) solutions and left for 16 hours at room temperature in the dark. A $3 \mathrm{~mL}$ ABTS solution was diluted with $180 \mathrm{~mL}$ ethanol to obtain an absorbance of $0.70 \pm 0.02$ at $734 \mathrm{~nm}$ by UV-Vis spectrophotometer (Spectroquant Pharo 300, Merck KGaA, Germany). The reaction mixtures were composed of $3 \mathrm{~mL}$ of $\mathrm{ABTS}^{\cdot+}$ solution and $200 \mu \mathrm{L}$ of extract or ascorbic acid at five different concentrations $(10,50,90$, 130 and $170 \mu \mathrm{g} / \mathrm{mL})$. The absorbance was measured at $734 \mathrm{~nm}$ using a UV-Vis spectrophotometer (Spectroquant Pharo 300, Merck KGaA, Germany) after 10 min with ethanol as the blank sample. The ABTS ${ }^{++}$ scavenging capacity of the extract was compared with ascorbic acid (positive control), and percentage inhibition was calculated as following equation:

$$
\% \text { ABTS }^{\bullet+} \text { inhibition }=\frac{A_{\text {blank }}-A_{\text {sample }}}{A_{\text {blank }}} \times 100
$$

Where $A_{\text {blank }}=$ Absorbance of the blank sample and $\mathrm{A}_{\text {sample }}=$ absorbance of the sample.

The $\mathrm{IC}_{50}$ value was calculated by the linear regression method through plots of the antiradical activity percentage against the concentration of the tested compounds.

\subsection{Palm olein sample preparation}

The mangrove apple fruit extracts $(100 \mathrm{ppm}$ and 200 ppm) were added directly into separate bottles that contained $500 \mathrm{~mL}$ palm olein (Bagus; Sime Darby, Malaysia). The oil samples were covered with aluminium foil and placed on an orbital shaker at 150 rpm for $60 \mathrm{~min}$ to ensure homogenous dispersion.

\subsection{Schaal oven test (accelerated storage)}

The oxidative stability of palm olein was monitored under accelerated storage at $65^{\circ} \mathrm{C}$ for 24 days according to Yim et al. (2013) method. A $500 \mathrm{~mL}$ of palm olein 
sample was poured into 15 amber glass bottles $(30 \mathrm{~mL})$ without headspace and cap for each MAFE concentration. The control sample $(500 \mathrm{~mL}$ palm olein without MAFE) was also poured into another 15 amber glass bottles. Then, the glass bottles were placed into an oven (Memmert, Germany) and subjected to accelerated oxidation at $65 \pm 2^{\circ} \mathrm{C}$ for 24 days. Oxidative changes were monitored by peroxide value, $p$-anisidine value, total oxidation value and absorbance at $232 \mathrm{~nm}$ (conjugated dienes) and $268 \mathrm{~nm}$ (conjugated trienes) analysis at 0 day and at regular intervals of 6 days for 24 days.

\subsection{Oxidative stability of palm olein}

\subsubsection{Peroxide value}

Peroxide value (PV) of the palm olein was determined according to AOCS Cd 8-53 (AOCS, 2005) and Tengku-Rozaina and Birch (2013) methods. A $5 \mathrm{~g}$ of oil sample was weighed into a $250 \mathrm{~mL}$ conical flask and mixed with $30 \mathrm{~mL}$ glacial acetic acid (Merck KGaA, Germany) and chloroform (R\&M Chemicals, United Kingdom) mixture with a ratio of $3: 2(\mathrm{v} / \mathrm{v})$. Saturated potassium iodide $(0.5 \mathrm{~mL}$; Bendosen Laboratory Chemicals, Malaysia) solution was added to the mixture, and the flask was shaken for $1 \mathrm{~min}$ before $30 \mathrm{~mL}$ of distilled water was added into it. The mixture was then titrated with $0.01 \mathrm{~N}$ sodium thiosulphate pentahydrate $\left(\mathrm{Na}_{2} \mathrm{~S}_{2} \mathrm{O}_{3} .5 \mathrm{H}_{2} \mathrm{O}\right)$ (R\&M Chemicals, United Kingdom) solution by constant shaking until yellow colour almost disappeared. Subsequently, $2.0 \mathrm{~mL}$ of $1 \%$ starch (R\&M Chemicals, United Kingdom) solution was added as an indicator and continue the titration with constant agitation until the blue colour turned to clear colour to release all iodine from the solvent layer. The endpoint of $\mathrm{Na}_{2} \mathrm{~S}_{2} \mathrm{O}_{3}$ was recorded. A blank solution was analysed under a similar condition as a control. The PV was calculated based on the equation below:

$$
\text { Peroxide value }=\frac{(\mathrm{S}-\mathrm{B}) \times \mathrm{N} \times 1000}{\text { weight of sample }(\mathrm{g})} \text { meq peroxide } / \mathrm{kg}
$$

Where $\mathrm{B}=$ the volume of titrant of blank $(\mathrm{mL}), \mathrm{S}=$ the volume of titrant of sample $(\mathrm{mL})$ and $\mathrm{N}=$ the normality of sodium thiosulphate solution.

\subsection{2 p-anisidine value}

The $p$-anisidine value $(p-\mathrm{AnV})$ in palm olein was determined according to AOCS Cd 18-90 (AOCS, 2005). $2.0 \mathrm{~g}$ of oil sample was weighed into a $25 \mathrm{~mL}$ volumetric flask. The oil sample was dissolved and diluted to volume with isooctane (2,2,4-trimethylpentane) (Merck KGaA, Germany). The absorbance $\left(\mathrm{A}_{\mathrm{b}}\right)$ of the oil solution was measured at $350 \mathrm{~nm}$ using a UV-Vis spectrophotometer (Spectroquant Pharo 300, Merck KGaA, Germany). Then, $5 \mathrm{~mL}$ of the oil solution and 5 $\mathrm{mL}$ of isooctane (blank solution) were transferred to each of two $10 \mathrm{~mL}$ test tubes, respectively. $1 \mathrm{~mL} 0.25 \% p$ anisidine in acetic acid (w/v) that prepared by mixing
$0.25 \mathrm{~g} p$-anisidine (Sigma-Aldrich, St. Louis, USA) in $100 \mathrm{~mL}$ glacial acetic acid, was added to each test tube and shaken. After 10 mins, the absorbance was measured at $350 \mathrm{~nm}$ against isooctane containing $p$-anisidine. The $p$-AnV was calculated using the equation as follows:

$$
p-\text { anisidine value }=\frac{25 \times\left(1.2 \mathrm{~A}_{\mathrm{s}}-\mathrm{A}_{\mathrm{b}}\right)}{\text { weight of sample }(\mathrm{g})}
$$

Where $\mathrm{A}_{\mathrm{s}}=$ the absorbance of oil solution after reaction with the $p$-anisidine reagent and $\mathrm{A}_{\mathrm{b}}=$ the absorbance of the oil solution.

\subsubsection{Total oxidation (TOTOX) value}

TOTOX value of oil sample was calculated based on the equation reported by Shahidi and Wanasundara (2002) as follows:

$$
\text { TOTOX value }=2 \mathrm{PV}+p-\mathrm{AnV}
$$

Where $\mathrm{PV}=$ peroxide value and $p$ - $\mathrm{AnV}=p$-anisidine value

\subsubsection{Conjugated dienes and trienes content}

Analyses of conjugated dienes and trienes were carried out according to Wang et al. (2018). Oil sample $(0.1 \mathrm{~g})$ was added with $10 \mathrm{~mL}$ isooctane. The absorbance of the solution was measured at 232 and $268 \mathrm{~nm}$ by UVVis spectrophotometer (Spectroquant Pharo 300, Merck $\mathrm{KGaA}$, Germany) for conjugated dienes and trienes, respectively.

\subsection{Statistical analysis}

All analyses were conducted in triplicates $(\mathrm{n}=3)$. The results were expressed as mean \pm standard deviation. Statistical analysis was carried out using MINITAB (Minitab Incorporated, Pennsylvania, USA) version 14 for Windows. A two-way analysis of variance (ANOVA) and Fisher's Least significant difference (LSD) multiple comparisons were performed to determine significant difference between samples for each measurement at the confidence level of $95 \%(p<0.05)$.

\section{Results and discussion}

3.1 Percentage of extraction yield, total flavonoid content and total phenolic content of MAFE

The percentage of extraction yield of MAFE was $6.34 \%$ of dry weight basis, which was lower than Wetwitayaklung et al. (2013) study on the flesh of ripe fruit $(21.77 \%)$. The differences may be due to the differences in the solvent used for extraction, where ethanol was used in the present study and methanol was used in Wetwitayaklung et al. (2013) study. The difference in extraction yield of the same species of fruits with the different solvent used might be due to the capability of the solvent used to dissolve endogenous 
compounds of fruits (Sultana et al., 2009).

The total flavonoid content (TFC) of MAFE in the present study was $26.06 \pm 0.30 \mathrm{mg}$ QCE/g extract. The TFC in the mangrove apple were different according to different species of Sonneratia. The TFC values in the extract of pericarp and seed of Sonneratia apetala were $14.6 \pm 0.9 \mathrm{mg} \mathrm{CE}$ (catechin equivalent) $/ \mathrm{g}$ extract and $30.6 \pm 0.7 \mathrm{mg} \mathrm{CE} / \mathrm{g}$ extract, respectively (Hossain et al., 2013). On the other hand, the TFC in the fruit extract of Sonneratia alba was $20.93 \pm 0.79 \mathrm{mg} \mathrm{CE} / \mathrm{g}$ extract (Liu et al., 2019). The TFC in the fruit extract (pericarp with seed) of Sonneratia caseolaris in the present study was considered high compared to other species. The high content TFC in the MAFE in the present study was probably due to the presence of bioactive compound flavones and luteolin 7-O- $\beta$-glucoside (cynaroside) responsible for intestinal $\alpha$-glucoside inhibitory action as reported by Sadhu et al. (2006) and Tiwari et al. (2010).

The total phenolic content (TPC) in the MAFE in the present study was $12.21 \pm 1.31 \mathrm{mg}$ GAE $/ \mathrm{g}$ extract. Wetwitayaklung et al. (2013) reported that the TPC values in the crude extracts of the flesh of ripe fruit and seed of Sonneratia caseolaris were $157.5 \pm 7.90 \mathrm{mg}$ GAE/ g crude extract and $208.2 \pm 6.40 \mathrm{mg} \mathrm{GAE} / \mathrm{g}$ crude extract, respectively. Meanwhile, Hossain et al. (2013) found the TPC in the pericarp and seed of Sonneratia apetala were $55.4 \pm 1.3 \mathrm{mg} \mathrm{GAE} / \mathrm{g}$ extract and $300.1 \pm 8.2 \mathrm{mg} \mathrm{GAE} / \mathrm{g}$ extract, respectively. The TPC of MAFE in the present study was lower than the TPC found in Wetwitayaklung et al. (2013) and Hossain et al. (2013) probably due to the differences in the solvent used for extraction as mentioned above. According to Sultana et al. (2013), a higher TPC was obtained when more polar solvents such as methanol were used as extraction solvent.

\subsection{DPPH radical scavenging assay and ABTS radical cation scavenging assay}

The half of maximal inhibitory concentration $\left(\mathrm{IC}_{50}\right)$ value is inversely related to its antioxidant activity. It is the amount of antioxidant required to decrease the antioxidant activity by $50 \%$, which is obtained by interpolation from a linear regression analysis. High antioxidant activity of the sample will have a low value of $\mathrm{IC}_{50}$ (Do et al., 2014). The $\mathrm{IC}_{50}$ value of DPPH assay in the MAFE was $31.16 \pm 0.76 \mu \mathrm{g} / \mathrm{mL}$ (Table 1) was lower than in the flesh of mangrove apple fruit $(84.74$ $\mu \mathrm{g} / \mathrm{mL}$ ) in Rahim and Abu Bakar (2018) study. This indicated that the MAFE in the present study had higher antioxidant activity than the extract in Rahim and Abu Bakar (2018) study on Sonneratia caseolaris sample. This is probably due to the whole fruit (fruit and seed) was used in the present study. The $\mathrm{IC}_{50}$ value of antioxidant activities of the fruit extract of Sonneratia caseolaris calculated from DPPH radical reaction was also higher than the $\mathrm{IC}_{50}$ value of $\mathrm{DPPH}$ assay of Sonneratia caseolaris $(4.17 \mu \mathrm{g} / \mathrm{mL})$ in Wetwitayaklung et al. (2013) study. This probably due to the different cultivation conditions, maturity stage, environmental conditions and postharvest management in the samples of both studies. According to Manganaris et al. (2013), field management system and growing season, such as temperature and carbon dioxide $\left(\mathrm{CO}_{2}\right)$ partial pressure, have a significant effect on the levels of antioxidants and phytochemical profile.

Table $1 . \mathrm{IC}_{50}$ values obtained from DPPH assay and $\mathrm{ABTS}{ }^{\circ}$ assay of mangrove apple fruit extract and ascorbic acid

\begin{tabular}{lcc}
\hline Sample & DPPH assay $(\mu \mathrm{g} / \mathrm{mL})$ & $\mathrm{ABTS}^{\circ+}$ assay $(\mu \mathrm{g} / \mathrm{mL})$ \\
\hline Extract & $31.16 \pm 0.76^{\mathrm{a}}$ & $97.32 \pm 3.27^{\mathrm{a}}$ \\
Ascorbic acid & $5.28 \pm 0.58^{\mathrm{b}}$ & $12.71 \pm 1.14^{\mathrm{b}}$ \\
\hline
\end{tabular}

The $\mathrm{IC}_{50}$ value of $\mathrm{ABTS}^{\circ+}$ assay in MAFE in the present study was $97.32 \pm 3.27 \mu \mathrm{g} / \mathrm{mL}$. Wetwitayaklung et al. (2013) reported that the $\mathrm{IC}_{50}$ of antioxidant activities in the flesh of unripe mangrove apple fruit and flesh of ripe mangrove apple fruit calculated from ABTS radical cation reaction were $426 \mu \mathrm{g} / \mathrm{mL}$ and $524.20 \mu \mathrm{g} / \mathrm{mL}$, respectively. The differences in the $\mathrm{IC}_{50}$ value of $\mathrm{ABTS}^{*+}$ assay in the present and previous studies probably due to the differences in the samples used. Wetwitayaklung et al. (2013) analysed the $\mathrm{IC}_{50}$ of $\mathrm{ABTS}^{\circ+}$ assay for fruit flesh and seed separately, whereas the sample in the present study was the combination of fruit flesh and seed. According to Rahim and Abu Bakar (2018), a higher antioxidant compound was found in the seed compared to the flesh of the fruit. In Rahim and Abu Bakar (2018) study, they found that the $\mathrm{IC}_{50}$ of $\mathrm{ABTS}^{\circ+}$ assay in seed was $10.52 \mu \mathrm{g} / \mathrm{mL}$, which was lower than the flesh of the fruit $(84.74 \mu \mathrm{g} / \mathrm{mL})$. The lower $\mathrm{IC}_{50}$ in seed might be due to better antioxidant therapy and acetylcholinesterase (AChE) inhibitor in it than other parts of tree extract (Wetwitayaklung et al., 2013). The antioxidant activity of MAFE was not as strong as the ascorbic acid (standard) due to the $\mathrm{IC}_{50}$ value of DPPH assay and $\mathrm{ABTS}^{\circ+}$ assay for MAFE was significantly higher $(p<0.05)$ than the $\mathrm{IC}_{50}$ value for the ascorbic acid.

\subsection{Oxidative stability of palm olein}

\subsubsection{Peroxide value}

Peroxide values (PV) of all palm olein samples in the present study were under 20 meq peroxide $/ \mathrm{kg}$ after 24 days of accelerated storage in $65^{\circ} \mathrm{C}$ (Figure 1), which indicated that the samples have not tasted as rancid. However, the palm olein was not considered as fresh oil after 12 days accelerated storage period due to the PV was over $10 \mathrm{meq}$ peroxide $/ \mathrm{kg}$. According to Egan et al. 
(1981), the PV for fresh oils is usually below $10 \mathrm{meq}$ peroxide $/ \mathrm{kg}$ and a rancid taste is noticeable when the PV is between 20 and 40 meq peroxide $/ \mathrm{kg}$.

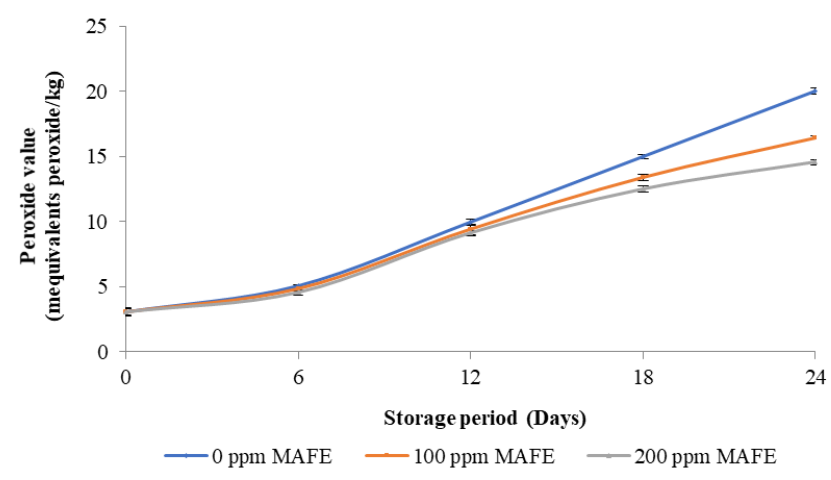

Figure 1. Peroxide value of palm olein during storage

There was no significant difference at day 0 of accelerated storage for all palm olein samples in the present study. However, the PV of control palm olein was significantly higher $(p<0.05)$ than the palm olein added with 100 ppm of MAFE after 18 days of accelerated storage and palm olein added with $200 \mathrm{ppm}$ of MAFE after six days of accelerated storage. Overall, the increase rate of PV was significantly less after 18 days of accelerated storage in the palm olein added with MAFE compared to the control sample. This finding indicated that the presence of MAFE had effectively slowed down the lipid oxidation which probably due to the high value of TFC and TPC as well as low $\mathrm{IC}_{50}$ value of DPPH assay and $\mathrm{ABTS}^{\cdot+}$ assay in MAFE.

There was a continuous increase in PV with the increase of the accelerated storage period observed for all the palm olein samples, and the data were significantly different $(p<0.05)$ at different storage period (Figure 1). The increase in PV of palm olein sample indicated the increasing formation of primary lipid oxidation product (hydroperoxide) as palm olein contained a high amount of monounsaturated fatty acids (MUFA) and polyunsaturated fatty acids (PUFA). The major MUFA and PUFA in palm olein are oleic acid (C18:1n9; 45.40 $\pm 0.20 \%$ ) and linoleic acid (C18:2n6; $10.20 \pm 0.10 \%$ ), respectively (Soares et al., 2009). The hydrogen abstraction or by addition of an oxygen radical initiates the chain reaction of lipid peroxidation, which causing the oxidative damage of PUFA since PUFA are more sensitive compared to than saturated fatty acids (Repetto et al., 2012).

The results obtained in the present study were similar to Womeni et al. (2016) findings on the addition of extract of soursop flower into the palm olein. Womeni et al. (2016) reported that the increase in PV slowed down across the storage period for the palm olein with soursop flower extract. However, the PV of the control sample obtained in the present study was lower compared to the PV in Womeni et al. (2016) study at the same storage duration. The PV of the control palm olein in Womeni et al. (2016) study increased to $27 \mathrm{meq}$ peroxide/ $\mathrm{kg}$ at day 10 . This finding is probably due to the differences of the oil manufacturers and locations of palm fruit that might affect the quality of palm olein. Akinola et al. (2010) reported that the PV of palm oil varied from different local factories in Western Nigeria, which tend to reflect the stability and quality of the palm oil. Furthermore, the storage temperature in oven was different from Womeni et al. (2016) study $\left(70^{\circ} \mathrm{C}\right.$ and 8 hrs heating cycle per day), whereas the temperature used in the present study was $65^{\circ} \mathrm{C}$. No antioxidant (e.g. BHA, BHT and TBHQ) and food additives were added at any stages of the manufacturing process in the palm olein samples used in the present study as claimed by the manufacturer. The results of PV in the present study are in agreement with those found in the literature (Fatihanim et al., 2009; Yim et al. 2013; Chong et al., 2015), which all results in previous studies showed the increase of PV slowed down across the storage period as the concentration of extract increased.

\subsection{2 p-anisidine value}

The $p$-anisidine value $(p-\mathrm{AnV})$ in the control palm olein after 24 days of accelerated stored was higher than food safety and quality range ( $p-\mathrm{AnV}=3.0$; Gotoh and Wada, 2006). This indicates that the control palm olein was not safe to be consumed as the palm olein began to deteriorate as more free fatty acid (FFA) formed, which affected the oil quality (Gotoh and Wada, 2006). Overall, the $p$-AnV began to rise gradually and significantly $(\mathrm{p}<$ 0.05 ) after 12 days of accelerated storage for all the oil samples in the present study (Figure 2). However, there were small significant differences $(\mathrm{p}<0.05)$ of $p$-AnV between day 0 and day 12 for palm olein with $100 \mathrm{ppm}$ of MAFE and between day 0 and day 6 for palm olein with $200 \mathrm{ppm}$ of MAFE. This indicated that the secondary oxidation of palm olein began after 12 days of accelerated storage. The occurrence of the secondary oxidation measured by $p-\mathrm{AnV}$ indicates the production of carbonyl, aldehydes (2-alkenals and 2,4-dienals),

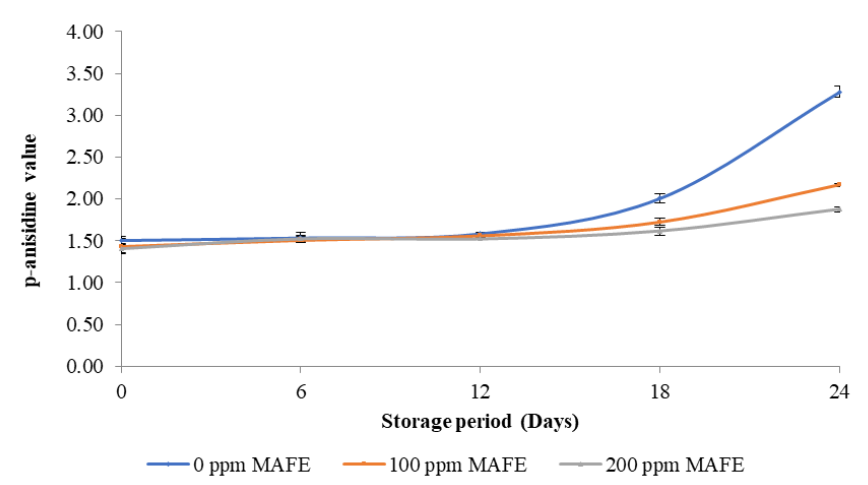

Figure 2. $p$-anisidine value of palm olein during storage 
ketones and carboxylic acids from decomposition of unsaturated fatty acids and hydroperoxide (Ling et al., 2015).

The trend of $p-A n V$ in the present study was in accordance with the PV, where the palm olein sample in the present study was not considered as fresh oil after 12 days of accelerated storage. However, the $p$-AnV of control palm olein increased significantly $(\mathrm{p}<0.05)$ at day 24 and was significantly higher $(p<0.05)$ than palm olein added with 100 ppm MAFE after 18 days of accelerated storage and palm olein added with $200 \mathrm{ppm}$ MAFE after 12 days of accelerated storage. This indicated that the MAFE had effectively retarded the secondary oxidation by delaying the decomposition of hydroperoxide as shown by the high values of TFC and TPC as well as low $\mathrm{IC}_{50}$ value of $\mathrm{DPPH}$ assay and $\mathrm{ABTS}^{\circ+}$ assay in MAFE.

The $p$-AnV of palm olein added with $200 \mathrm{ppm}$ of MAFE was significantly lower $(\mathrm{p}<0.05)$ than palm olein added with $100 \mathrm{ppm}$ of MAFE and control sample at day 24 of storage, which indicated that the higher concentration of MAFE had better protection effect against lipid oxidation. The finding in the present study was in agreement with the previous studies (Yim et al., 2013; Chong et al., 2015; Guo et al., 2016; Womeni et al., 2016), where the increase of $p-\mathrm{AnV}$ in palm olein and sunflower oil were lower with the higher concentration of the extract.

\subsubsection{Total oxidation (TOTOX) value}

The TOTOX value increased significantly $(\mathrm{p}<$ 0.05 ) at different storage periods in a regular pattern for all the three palm olein samples in the present study (Figure 3). The trend of TOTOX value in the present study was following the trend of PV. The TOTOX value of control palm olein was significantly higher $(\mathrm{p}<0.05)$ than palm olein added with 100 ppm MAFE after 18 days of accelerated storage. However, palm olein added with 200 ppm MAFE had significantly lower $(\mathrm{p}<0.05)$ TOTOX value than control palm olein throughout the accelerated storage periods, which indicated the palm

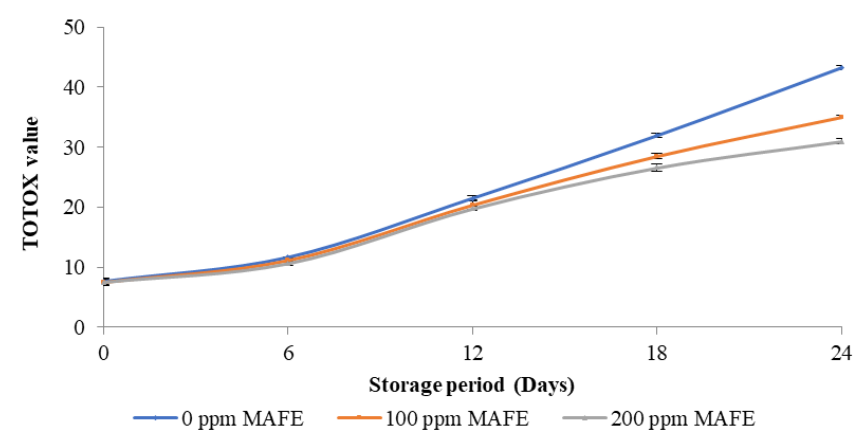

Figure 3. Total oxidation (TOTOX) value of palm olein during storage olein with a higher concentration of MAFE had better protection against lipid oxidation. The results of the present study showed that the addition of MAFE in the palm olein samples had effectively delayed the lipid oxidation of palm olein compared to the control sample. This was because of the high value of TFC and TPC as well as low $\mathrm{IC}_{50}$ value of DPPH assay and $\mathrm{ABTS}^{\circ+}$ assay in MAFE. The results in the present study were in accordance with previous studies (Chong et al., 2015; Womeni et al., 2016), as the higher the concentration of extract, the lower the TOTOX value of palm olein and sunflower oil.

\subsubsection{Conjugate dienes and trienes}

Generally, the peroxide that was produced at the initial stage of oxidation had absorption at $232 \mathrm{~nm}$. Therefore, the absorbance at $232 \mathrm{~nm}$ can be used to measure the degree of primary oxidation and also conjugated dienes (Guo et al., 2016). Meanwhile, the secondary oxidation of oil can be detected by measuring the absorbance at $268 \mathrm{~nm}$. However, it is not similar to $p$ -anisidine value analysis in theoretically due to the ketones are not monitored in the $p$-anisidine analysis. The absorbance at $268 \mathrm{~nm}$ can measure the diethylenic ketones and conjugated trienes (Jaswir et al., 2000; Guo et al., 2016).

The results of the present study showed there was a significant increase $(p<0.05)$ of absorbance at $232 \mathrm{~nm}$ along the accelerated storage period (Figure 4). The trend of the increasing absorbance values at $232 \mathrm{~nm}$ was similar to the peroxide value. The absorbance values at $232 \mathrm{~nm}$ of all the oil samples in the present study were significantly different $(p<0.05)$ between each duration period. The indicated that the conjugated diene content was continuously increased along the accelerated storage period. However, the increase of absorbance at $232 \mathrm{~nm}$ was smaller compared to the peroxide value after 18 days of accelerated storage. This difference was because less increased of the diene content during the late stage of lipid oxidation (Guo et al., 2016).

There was no significant difference $(\mathrm{p}>0.05)$

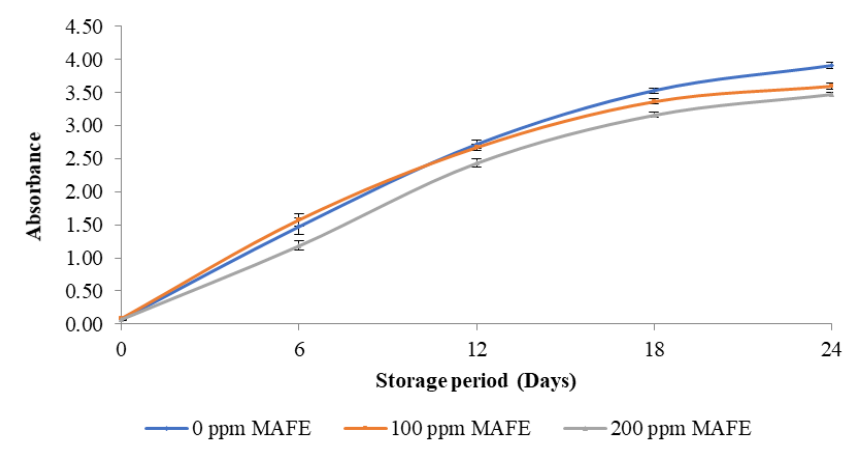

Figure 4. Conjugated diene content of palm olein during storage 
between the control sample and palm olein added with $100 \mathrm{ppm}$ of MAFE from day 0 to day 12 in the present study. However, the control sample was significantly higher $(p<0.05)$ than the palm olein added with 200 ppm of MAFE along the accelerated storage period. This indicated that a higher concentration of MAFE was more effectively to slow down the increases of diene content. Meanwhile, the absorbance at $232 \mathrm{~nm}$ in palm olein with $100 \mathrm{ppm}$ MAFE added was close to in palm olein with 200 ppm MAFE in day 24.

The absorbance value at $268 \mathrm{~nm}$ in the present study was increased significantly $(\mathrm{p}<0.05)$ during storage period except for palm olein added with 100 ppm MAFE (Figure 5). There was no significant difference in the absorbance value for palm olein added with $100 \mathrm{ppm}$ of MAFE at day 12 and 18 of storage. However, the absorbance increased again between day 18 to 24 of storage duration. This is probably due to the decomposition of ketone as oxidation can destroy the double bond between carbon and oxygen. Nevertheless, the production rate of ketones was higher than the decomposition rate of them (Guo et al., 2016). Hence, the absorbance value was increased at day 24 of storage.

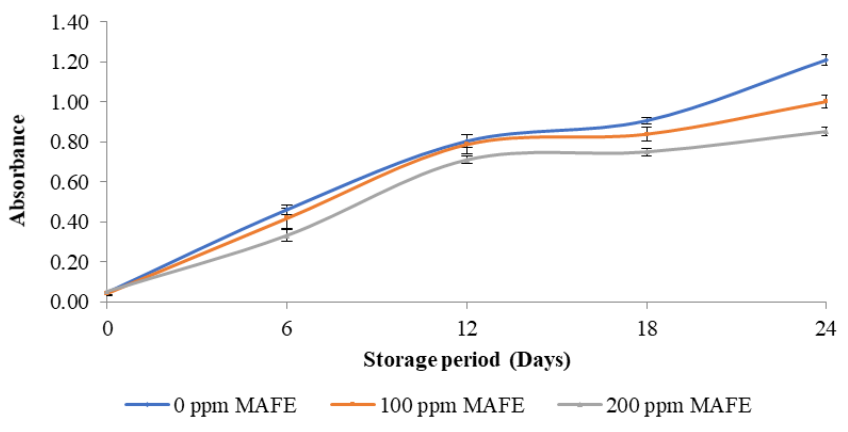

Figure 5. Conjugated triene content of palm olein during storage

The results of absorbance at $268 \mathrm{~nm}$ were similar to absorbance $232 \mathrm{~nm}$, where the absorbance of the control sample was significantly higher $(\mathrm{p}<0.05)$ than palm olein added with $100 \mathrm{ppm}$ of MAFE after day 12, and with palm olein added with 200 ppm of MAFE throughout the storage period. This indicated that a higher concentration of MAFE was more effective to reduce the increase of ketones. Moreover, a continuous reduction of ketones is produced by ethanol extract (Urbančič et al., 2014). The finding in the present study was in accordance with Wang et al. (2018), which the highest concentration of Coriandrum sativum L. extract (1200 ppm) significantly decreased the conjugated diene and triene content at absorbance of $232 \mathrm{~nm}$ and $268 \mathrm{~nm}$ as compared to $300 \mathrm{ppm}$ and $600 \mathrm{ppm}$ of extract.

\section{Conclusion}

The results of the present study showed that the crude extract from mangrove apple fruit (MAFE) contained a good amount of total flavonoid content and total phenolic content. Moreover, the MAFE have antioxidant activity as the DPPH and $\mathrm{ABTS}^{\circ+}$ assay showed a positive result. The findings of the present study revealed that the MAFE was capable of reducing the lipid oxidation of commercial palm olein. The peroxide value, $p$-anisidine value, total oxidation value, conjugated dienes and conjugated trienes in the palm olein samples added with MAFE were significantly lower than the control palm olein sample at the late stage of the storage period, which was after 18 days of accelerated storage at $65^{\circ} \mathrm{C}$. The palm olein samples added with MAFE still can be consumed because the peroxide value and $p$-anisidine value did not exceed the food safety and quality range. Furthermore, there was a significant difference between palm olein sample added with $100 \mathrm{ppm}$ and $200 \mathrm{ppm}$ of MAFE at day 24 of storage. Therefore, the higher concentration of MAFE added, the more effective the protective effect against lipid oxidation as $200 \mathrm{ppm}$ of MAFE showed the lowest value of all the responses for oxidative stability analysis. In conclusion, the MAFE from mangrove apple fruit can be used as a natural antioxidant to prolong the shelf life of the palm olein.

\section{Conflict of Interest}

The authors declare no conflict of interest.

\section{Acknowledgements}

The authors would like to thank the Faculty of Fisheries and Food Science, Universiti Malaysia Terengganu (UMT) for the funding and the laboratory staff for their technical assistance in this study.

\section{References}

Akinola, F.F., Oguntibeju, O.O., Adisa, AW and Owojuyigbe, O.S. (2010). Physico-chemical properties of palm oil from different palm oil local factories in Nigeria. Journal of Food, Agriculture and Environment, 8 (3 and 4), 264-269.

AlShaal, S., Karabet, F. and Daghestani, M. (2019). Determination of the antioxidant properties of the syrian olive leaves extracts and isolation oleuropein by HPLC techniques. Analytical and Bioanalytical Chemistry Research, 6(1), 97-110.

AOCS (American Oil Chemists' Society). (2005). Official methods and recommended practices of the AOCS. Champaign, Ill: American Oil Chemists' Society.

Anokwuru, C.P., Anyasor, G.N., Ajibaye, O., Fakoya, O. and Okebugwu, P. (2011). Effect of extraction 
solvents on phenolic, flavonoid and antioxidant activities of three Nigerian medicinal plants. Nature and Science, 9(7), 53-61.

Che Man, Y.B. and Jaswir, I. (2000). Effect of rosemary and sage extracts on frying performance of refined, bleached and deodorised (RBD) palm olein during deep-fat frying. Food Chemistry, 69(3), 301 - 307. https://doi.org/10.1016/S0308-8146(99)00270-8

Che Man, Y.B. and Tan, C.P. (1999). Effects of natural and synthetic antioxidants on changes in refined, bleached, and deodorised palm olein during deep-fat frying of potato chips. Journal of American Oil Chemists' Society, 76(3), 331 - 339. https:// doi.org/10.1007/s11746-999-0240-y

Chong, Y.-M., Chang, S.-K., Sia, W.C.-M. and Yim, H.S. (2015). Antioxidant efficacy of mangosteen (Garcinia mangostana Linn.) peel extracts in sunflower oil during accelerated storage antioxidant efficacy of mangosteen peel extracts. Food Bioscience, 12, 18-25. https://doi.org/10.1016/ j.fbio.2015.07.002

Dam Roy, S., Krishnan, P., George, G., Kaliyamoorthy, M. and Bharathi, G.M.P. (2009). Mangroves of Andaman and Nicobar Islands. India: Central Agricultural Research Institute.

Damanik, M. and Murkovic, M. (2018). The stability of palm oils during heating in a Rancimat. European Food Research and Technology, 244(7), 1293-1299. https://doi.org/10.1007/s00217-018-3044-1

Do, Q.-D., Angkawijaya, A.E., Tran-Nguyen, P.L., Huynh, L.H., Soetaredjo, F.E., Ismadji, S. and Ju, Y. -H. (2014). Effect of extraction solvent on total phenol content, total flavonoid content and antioxidant activity of Limnophila aromatica. Journal of Food and Drug Analysis, 22(3), 296-302. https://doi.org/10.1016/j.jfda.2013.11.001

Egan, H., Kirk, R.S. and Sawyer, R. (1981). Person's Chemical Analysis of Food. 8th ed., New York: Churchill Livingstone.

Fatihanim, M.N., Suhaila, M., Nor Aini, I. and Razali, I. (2009). Antioxidative properties of Curcuma longa leaf extract in accelerated oxidation and deep frying studies. Journal of American Oil Chemists' Society, 86(2), 141-147. https://doi.org/10.1007/s11746-0081335-6

Gan, H.L., Tan, C.P., Che Man, Y.B., Nor Aini, I. and Nazimah, S.A.H. (2005). Monitoring the storage stability of RBD palm olein using the electronic nose. Food Chemistry, 89(2), 271-282. https:// doi.org/10.1016/j.foodchem.2004.02.034

Gotoh, N. and Wada, S. (2006). The importance of peroxide value in assessing food quality and food safety. Journal of American Oil Chemists' Society, 83(5), 473-474. https://doi.org/10.1007/s11746-006-
1229-4

Guo, Q., Gao, S., Sun, Y.-W., Gao, Y.-F., Wang, X.-R. and Zhang, Z.-S. (2016). Antioxidant efficacy of rosemary ethanol extract in palm oil during frying and accelerated storage. Industrial Crops and Products, 94, 82-88. https://doi.org/10.1016/ j.indcrop.2016.08.032

Hossain, S.J., Basar, M.H., Rokeya, B., Arif, K.M.T., Sultana, M.S. and Rahman, M.H. (2013). Evaluation of antioxidant, antidiabetic and antibacterial activities of the fruit of Sonneratia apetala (Buch.Ham.). Oriental Pharmacy and Experimental Medicine, 13(2), 95-102. https://doi.org/10.1007/ s13596-012-0064-4

Hou, D.X. (2003). Potential Mechanisms of cancer chemoprevention by anthocyanins. Current Molecular Medicine, 3(2), 149-159. https:// doi.org/10.2174/1566524033361555

Jariyah, Widjanarko, S.B., Yunianta, Estiasih, T. and Sopade, P.A. (2014). Pasting properties mixtures of mangrove fruit flour (Sonneratia caseolaris) and starches. International Food Research Journal, 21 (6), 2161-2167.

Jaswir, I., Che Man, Y.B. and Kitts, D.D. (2000). Use of natural antioxidants in refined palm olein during repeated deep-fat frying. Food Research International, 33(6), $501 \quad-\quad 508 . \quad \mathrm{https} / /$ doi.org/10.1016/S0963-9969(00)00075-2

Ling, S.S.-C. Chang, S.-K., Sia, W.C.-M. and Yim, H.-S. (2015). Antioxidant efficacy of unripe banana (Musa acuminate Colla) peel extracts in sunflower oil during accelerated storage. Acta Scientiarum Polonorum, Technologia Alimentaria, 14(4), 343 356. https://doi.org/10.17306/J.AFS.2015.4.34

Liu, J.-J., Luo, D.-D., Wu, Y.-L., Gao, C.-J., Lin, G.-S., Chen, J.-F., Wu, X.-L., Zhang, Q., Cai, J. and Su, Z.R. (2019). The protective effect of Sonneratia apetala fruit extract on acetaminophen-induced liver injury in mice. Evidence-Based Complementary and Alternative Medicine, 2019, 6919834. https:// doi.org/10.1155/2019/6919834

Makahleh, A., Saad, B. and Bari, M.F. (2015). Synthetic phenolics as antioxidants for food preservation. In Sahidi, F. (Ed.) Handbook of Antioxidants for Food Preservation, p. 51-78. USA: Woodhead Publishing. https://doi.org/10.1016/B978-1-78242-089-7.000038

Manganaris, G.A., Goulas, V., Vicente, A.R. and Terry, L.A. (2013). Berry antioxidants: small fruits providing large benefits. Journal of the Science of Food and Agriculture, 94(5), 825-833. https:// doi.org/10.1002/jsfa.6432

Maskan, M. and Horuz, E. (2017). Evaluation of antioxidant properties of Za'atar (Thymbra spicata) 
essential oils as natural antioxidant for stability of palm olein during deep-fat frying process. Journal of Food Science and Technology, 54(7), 1794-1801. https://doi.org/10.1007/s13197-017-2608-6

Minh, N.P. (2019). Investigation of mangrove apple (Sonneratia caseolaris) juice production. Journal of Pharmaceutical Sciences and Research, 11(3), 809812.

Rahim, A.C. and Abu Bakar, M.F. (2018). Pidada Sonneratia caseolaris. In Rodrigues, S., Silva, E.D.O. and Brito, E.S.D. (Ed.) Exotic Fruits Reference Guide, p. 327-332. USA: Academic Press. https://doi.org/10.1016/B978-0-12-803138-4.000435

Repetto, M., Semprine, J. and Boveris, A. (2012). Lipid Peroxidation: Chemical Mechanism, Biological Implications and Analytical Determination. In Catala, A.. (Ed.) Lipid Peroxidation, p. 3-30. InTech Open E-Book. https://doi.org/10.5772/45943

Sadhu, S.K., Ahmed, F., Ohtsuki, T. and Ishibashi, M. (2006). Flavonoids from Sonneratia caseolaris. Journal of Natural Medicine, 60, 264-265. https:// doi.org/10.1007/s11418-006-0029-3

Shahidi, F. and Wanasundara, U.N. (2002). Methods for measuring oxidative rancidity in fats and oils. In Akoh, C.C and Min, D.B. (Eds.). Food Lipids: Chemistry, Nutrition and Biotechnology, p. 465-487. New York, USA: Marcel Dekker Inc. https:// doi.org/10.1201/9780203908815.ch14

Simlai, A., Rai, A., Mishra, S., Mukherjee, K. and Roy, A. (2014). Antimicrobial and antioxidative activities in the bark extracts of Sonneratia caseolaris, a mangrove plant. EXCLI Journal, 13, 997-1010.

Soares, F.A.S.D.M, da Silva, R.C., da Silva, K.C.G., Lourenço, M.B., Soares, D.F. and Gioielli, L.A. (2009). Effects of chemical interesterification on physicochemical properties of blends of palm stearin and palm olein. Food Research International, 42(9), 1287-1294. j.foodres.2009.03.022

Sultana, B., Anwar, F. and Ashraf, M. (2009). Effect of Extraction Solvent/Technique on the Antioxidant Activity of Selected Medicinal Plant Extracts. Molecules, 14(6), 2167-2180. https:// doi.org/10.3390/molecules14062167

Tan, C.P., Che Man, Y.B., Selamat, J. and Yusoff, M.S.A. (2002). Comparative studies of oxidative stability of edible oils by differential scanning calorimetry and oxidative stability index methods. Food Chemistry, 76(3), 385 - 389. https:// doi.org/10.1016/S0308-8146(01)00272-2

Tengku-Rozaina, T.M. and Birch, E.J. (2013), Physicochemical characterisation and oxidative stability of refined hoki oil, unrefined hoki oil and unrefined tuna oil. International Journal of Food Science and Technology, 48(11), 2331-2339. https:// doi.org/10.1111/ijfs.12222

Thuoc, D.V., Ngoc Mai, N.T., Viet Ha, L.T., Hung, L.D., Tra, D.H., Hung, N.K. and Hung, N.P. (2018). Evaluation of antibacterial, antioxidant and antiobese activities of the fruit juice of crabapple mangrove Sonneratia caseolaris (Linn.). International Journal of Agricultural Sciences and Natural Resources, 5 (2), 25-29.

Tiwari, A.K., Viswanadh, V., Gowri, M.P., Ali, A.Z., Radhakrishnan, S.V.S., Agawane, S.B., Madhusudana, K. and Rao, J.M. (2010). Oleanolic acid - An $\alpha$-glucosidase inhibitory and antihyperglycemic active compound from the fruits of Sonneratia caseolaris. Journal of Medicinal and Aromatic Plants, 1(1), 19-23.

Urbančič, S., Kolar, M.H., Dimitrijević, D., Demšar, L. and Vidrih, R. (2014). Stabilisation of sunflower oil and reduction of acrylamide formation of potato with rosemary extract during deep-fat frying. Food Science and Technology, 57(2), 671-678. https:// doi.org/10.1016/j.lwt.2013.11.002

Wang, D.-Y., Fan, W.-C., Guan, Y.-F., Huang, H.N., Yi, T. and Ji, J.-M. (2018). Oxidative stability of sunflower oil flavored by essential oil from Coriandrum sativum L. during accelerated storage. Food Science and Technology, 98, 268-275. https:// doi.org/10.1016/j.lwt.2018.08.055

Wetwitayaklung, P., Limmatvapirat, C. and Phaechamud, T. (2013). Antioxidant and anticholinesterase activities in various parts of Sonneratia caseolaris (L.). Indian Journal of Pharmaceutical Sciences, 75(6), 649-656.

Womeni, H.M., Tonfack Djikeng, F., Iruku, N.S.S.P., Karuna, M.S.L., Prasad, R.B.N. and Linder, M. (2016). Valorisation of soursop flowers (Annona muricata L.) as potent source of natural antioxidants for stabilisation of palm olein during accelerated storage. Food Science and Nutrition, 4(6), 802-810. https://doi.org/10.1002/fsn3.349

Wu, S.-B., Wen, Y., Li, X.-W., Zhao, Y., Zhao, Z. and $\mathrm{Hu}$, J.-F. (2009). Chemical constituents from the fruits of Sonneratia caseolaris and Sonneratia ovata (Sonneratiaceae). Biochemical Systematics and Ecology, 37(1), 1-5. https://doi.org/10.1016/ j.bse.2009.01.002

Yim, H.-S., Chye, F.-Y., Liow, M.-L. and Ho, C.-W. (2013). Antioxidant potential of Pleurotus porrigens extract and application in sunflower oil during accelerated storage. Chiang Mai Journal Science, 40 (1), 34-48. 